\title{
Long-Term Follow-Up of Adolescent and Adult Patients with Cystic Fibrosis: A Single Center's Experience
}

\begin{tabular}{|c|c|c|}
\hline Author (s) & \multicolumn{2}{|c|}{ 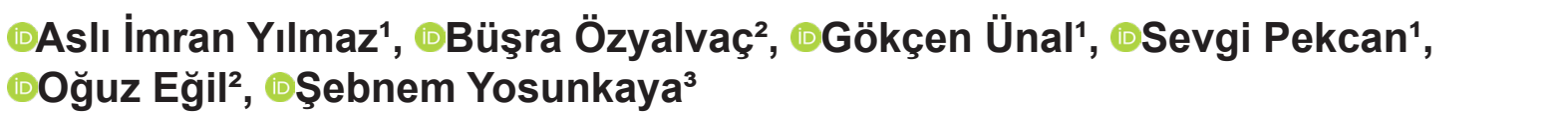 } \\
\hline $\begin{array}{l}\text { Affiliation } \\
\text { (s) }\end{array}$ & \multicolumn{2}{|c|}{$\begin{array}{l}\text { 1Department of Pediatric Pulmonology, Meram Faculty of Medicine, Necmettin Erbakan University, Konya, Turkey } \\
\text { 2Department of Pediatrics, Meram Faculty of Medicine, Necmettin Erbakan University, Konya, Turkey } \\
\text { 3Department of Pulmonology, Meram Faculty of Medicine, Necmettin Erbakan University, Konya, Turkey }\end{array}$} \\
\hline $\begin{array}{c}\text { Article } \\
\text { Information }\end{array}$ & $\begin{array}{l}\text { Article Type: Original Articles } \\
\text { Article Group: Pediatric Pulmonology }\end{array}$ & $\begin{array}{l}\text { Received: } 22.02 .2021 \\
\text { Accepted: } 03.06 .2021 \\
\text { Available Online: } 29.08 .2021\end{array}$ \\
\hline
\end{tabular}

\section{Abstract}

Cystic fibrosis (CF) is a chronic disease with autosomal recessive inheritance, chlorine duct defect, and multisystemic involvement. In this study, we evaluated the problems of our adolescent and adult patients with CF who were followed up in our unit to determine their problems at the regional level, to better observe their treatments, and to offer solutions for complications that occurred during their follow-up. Sixty-five patients with CF (50 adolescents and 15 adults) who consulted our clinic between September 2008 and November 2020 were included in this study, and their retrospective data were reviewed and saved. The mean age of the patients was $17.2 \pm 6.21$ years, and the mean age at diagnosis was 7.1 years. Nearly three-quarters $(73.8 \%)$ of the patients were adolescents, $26.2 \%$ were adults. Their mean body mass index (BMI) was $18.81 \pm 4.06 \mathrm{~kg} / \mathrm{m} 2$. The mean $\mathrm{FEV}$, was $82.94 \pm 25.22 \%$ in the adolescent group and $64.47 \pm 28.47 \%$ in the adult group. Pseudo-Bartter syndrome was the most common clinical presentation in adolescents (44\%) and productive cough $28.6 \%$ was most common in adults. The rate of bronchiectasis was $73.6 \%$ in the adults and $29.2 \%$ in the adolescents. CF-related diabetes was seen in $33.3 \%$ of the adults and $8.3 \%$ of the adolescents. Gastroesophageal reflux disease was present in $25.5 \%$ of the adolescents, but it was not seen in the adults. Mortality was $20.0 \%$ in the adult group and $4.1 \%$ in the adolescents. There was no significant difference between the groups regarding BMI, chronic pseudomonas colonization, and pulmonary exacerbation. In both groups, the most common allele $(21.8 \%)$ was delf508. We saw that the disease complications were less in the adolescent group. We thought that early diagnosis and treatment were related to this condition.

Keywords: Cystic fibrosis, adults, adolescents

Correspondence: Aslı İmran Yılmaz, Necmettin Erbakan University, Meram Faculty of Medicine, Department of Pediatrics, Division of Pediatric Pulmonology, Yunus Emre mah. No:281, 42090, Meram, Konya, Turkey 


\section{Introduction}

Cystic fibrosis has an autosomal recessive inheritance model with an incidence varying between populations, and it is common in Caucasians. ${ }^{1}$ A protein called cystic fibrosis transmembrane conductance regulator (CFTR) is synthesized from the CF gene. ${ }^{2,3}$ Structural and functional disorder in the CFTR protein leads to the disruption of the ion transport in the epithelial cell plasma membrane of the organs such as lungs, pancreas, liver, intestines, sweat glands, and epididymis. ${ }^{4}$

According to the reports of the Cystic Fibrosis Foundation Patient Registry (CFFPR), the total number of patients diagnosed as having CF in 2018 was 30,770 . Some $54.6 \%$ of these patients were adults. The number of adult patients has

Highlights
- Cystic fibrosis is more mortal in the late
diagnosed adult patient group
- Early diagnosis and treatment increases
life expectancy by reducing disease
complications.
- As in childhood, the adult patient group
should also be followed up with a
multidisciplinary approach.

\section{Material and Method}

Necmettin Erbakan Üniversity,Meram Faculty of Medicine Ethics Committee was obtained for this study (Date:18.09.2020, Decision No:2020/2815).

In accordance with the definition of the American Academy of Pediatrics (AAP), we grouped our patients as adolescents between the ages of $10-18$ years and adults as those aged over 18 years. ${ }^{11}$ This study included 50 adolescents and 15 adult patients with CF, who had presented to our clinic between September 2008 and November 2020. The outpatient clinic records of the last one year were examined.

These files were reviewed retrospectively, and information within the period between the time of diagnosis and the last follow-up increased in recent years, but pediatric patient numbers have remained stable. Similarly, it was found that among the total population of $293,028,000$ in the United States of America, there were 23,347 patients with CF, with a prevalence of $0.797 / 10,000$, and its frequency was $1 / 3000 .^{5}$ According to the 2017 results for the Central Anatolia Region of Turkey, the frequency was $2.9 / 10,000$ (1/3400 live births). ${ }^{6}$

The most involved organ in CF is the lungs, but clinical findings vary according to the patient's age, genetic mutation, involved systems, and disease severity. ${ }^{7}$ Many factors determine the amount of lung damage in CF. It is known that the pulmonary disease of individuals with severe mutations progresses rapidly, and the respiratory problems individuals with slight mutations are at a light level. ${ }^{8}$ However, the mutation type is not effective alone in determining lung damage. Apart from the type of mutation, female sex, pancreatic failure, growth retardation, poor environmental conditions (encountering microorganisms, exposure to cigarette smoke, incompliance with treatment at a young age), not being able to bring diabetes under control, and mutations in other regulator genes that affect the anti-inflammatory and antioxidant systems are other factors that causing rapid disruptions of pulmonary functions. ${ }^{9}$

Although life expectancy was very low in CF in previous years, it has increased as a result of the early recognition of the disease through the inclusion of CF in newborn screening programs, developments in treatment, developed respiratory physiotherapy methods, the increase in the foundation of CF follow-up centers, and improvements in disease consciousness by informing patients and their families. It has also become a multidisciplinary topic involving endocrinology, gynecology, urology, general surgery, and especially chest diseases, regarding the follow-up and treatment of patients other than children. In our country, Turkey, CF was included in the screening program in $2015 .^{10}$

In our study, we aimed to retrospectively examine adolescent patients followed up in our Pediatric Chest Diseases unit and adult patients with CF. was recorded. When CF was first suspected, all patients were diagnosed using the quantitative sweat chloride test in addition to clinical findings, and mutation examinations were performed for all patients. The patients were monitored in 3-month routine follow-ups, and the patients' clinical characteristics, examination findings, laboratory examinations, mutation analysis results, ultrasound results, sputum culture results, respiratory function tests, treatments, and complications that emerged during followup were recorded in their files at each appointment.

\section{Statistical Analysis}

The SPSS 2022 software package was used in the evaluation of numerical data. Student's t-test was used when numerical data were normally distributed, and the Mann-Whitney $U$ test was used when they were not distributed normally. The Chi-square test was used for the evaluation of categorical data. $\mathrm{P}<0.05$ was considered statistically significant.

\section{Results}

A total of 258 patients with CF were being monitored in our clinic. Sixty-five patients - 50 adolescents and 15 adults - were included in the study. This group accounted for $25.1 \%$ of the total patient number $(6.5 \%$ were adults, and $18.6 \%$ were adolescents). Of the patients included in the study, $26.2 \%$ were adults, and $73.8 \%$ were adolescents, $44.6 \%(n=29)$ were male and $55.4 \%(n=36)$ were female. A family relation was present among $6.9 \%$ of the total number of patients (brothers/cousins). The mean age of our patients was $17.2 \pm 6.21$ (range, 10.5-43) years, and the mean age at diagnosis was $7.05 \pm 8.93$ years (median: 2.5 years; range, 1 month - 40 years). Five (7.6\%) patients died. Eight (12.3\%) patients did not attend their follow-ups regularly. Table 1 shows the epidemiological and clinical characteristics of the patients.

The most common symptom at presentation was pseudoBartter syndrome (PBS) at a rate of $30 \%$, which was followed by the medical history of the sibling at a rate of $15 \%$, and then frequent pneumonia and growth and developmental delay. Diagnostic symptom and findings of the patients were shown in Figure 1. 
Table 1.

The epidemiological and clinical characteristics of CF patients

\begin{tabular}{|c|c|c|c|c|}
\hline RESULTS & Total & Adolescent & Adult & p \\
\hline Number & 65 & $50(73.8 \%)$ & $15(26.2 \%)$ & \\
\hline Sex F/M & $55.3 \% / 44.7 \%$ & $42.1 \% / 47.9 \%$ & $60 \% / 40 \%$ & \\
\hline Mean age & $\begin{array}{c}7.05 \pm 8.93 \\
\text { (1 month- } 40 \text { years }\end{array}$ & $4.18 \pm 4.87$ & $16.28 \pm 12.41$ & 0.001 \\
\hline Median age & 2.5 & 0.84 & 15 & \\
\hline $\begin{array}{l}\text { Last age } \\
\text { Min: } \\
\text { Max: } \\
\text { Mean: }\end{array}$ & $\begin{array}{c}10 \text { years, } 3 \text { months } \\
43 \text { years } \\
14.9 \text { years }\end{array}$ & $\begin{array}{c}10.25 \text { months } \\
17 \text { years } \\
13.3 \pm 2.11 \text { years }\end{array}$ & $\begin{array}{c}18 \\
43 \\
24.96 \pm 6.78\end{array}$ & \\
\hline Clinical presentation & $\begin{array}{c}\text { PSB: } 24.5 \% \\
\text { Growth retardation: } 11.8 \% \\
\text { Relative: } 10.9 \%\end{array}$ & $\begin{array}{c}\text { PSB: } 44 \% \\
\text { Relative: } 14.9 \% \\
\text { Growth retardation: } 8.5 \%\end{array}$ & $\begin{array}{l}\text { Productive cough: } 28.6 \% \\
\text { Relative: } 21.4 \% \\
\text { Infertility: } 21.4 \%\end{array}$ & 0.004 \\
\hline Mean FEV1 & $82.94 \pm 25.22$ & $88.71 \pm 21.33$ & $64.47 \pm 28.47$ & 0.001 \\
\hline Mean BMI & $18.81 \pm 4.06$ & $\begin{array}{l}F: 17.85 \pm 4.48 \\
M: 18.45 \pm 3.17\end{array}$ & $\begin{array}{l}F: 22.29 \pm 3.03 \\
M: 19.03 \pm 4.87\end{array}$ & $>0.05$ \\
\hline Pseudomonas colonization & $39.3 \%(n=24)$ & $36.2 \%(n=17)$ & $50 \%(n=7)$ & $>0.05$ \\
\hline MRSA & $14.5 \%(n=9)$ & $14.9 \%(n=7)$ & $13.3 \%(n=2)$ & $>0.05$ \\
\hline pulmonary exacerbation (last year) & $24.5 \%(n=16)$ & $22.9 \%(n=11)$ & $33.3 \%(n=5)$ & $>0.05$ \\
\hline Asthma & $37.1 \%(n=23)$ & $38.5 \%(n=18)$ & $33.3 \%(n=5)$ & $>0.05$ \\
\hline GERD & $19.7 \%(n=12)$ & $25.5 \%(n=12)$ & 0 & 0.004 \\
\hline CFRD & $14.3 \%(n=9)$ & $8.3 \%(n=4)$ & $33.3 \%(n=5)$ & 0.017 \\
\hline Sinusitis & $36.8 \%(n=23)$ & $39.6 \%(n=19)$ & $26.7 \%(n=4)$ & $>0.05$ \\
\hline Polyp & $20.6 \%(n=13)$ & $20.8 \%(n=10)$ & $20.0 \%(n=3)$ & $>0.05$ \\
\hline Polypectomy & $7.9 \%(n=5)$ & $8.3 \%(n=4)$ & $6.6 \%(n=1)$ & $>0.05$ \\
\hline Pancreatitis & $15.3 \%(n=10)$ & $14.5 \%(n=7)$ & $20.0 \%(n=3)$ & $>0.05$ \\
\hline Z score & $-1.0 \pm 1.38$ & $-0.98 \pm 1.27$ & $-1.07 \pm 1.73$ & $>0.05$ \\
\hline Bronchiectasis & $39.7 \%(n=25)$ & $29.2 \%(n=14)$ & $73.6 \%(n=11)$ & 0.035 \\
\hline Mortality & $7.6 \%(n=5)$ & $4.1 \%(n=2)$ & $20.0 \%(n=3)$ & 0.004 \\
\hline Mutations & $\begin{array}{l}\text { Delf508: } 23.1 \% \\
\text { N1303K: } 8.7 \% \\
\text { G85E: } 7.1 \%\end{array}$ & $\begin{array}{l}\text { Delf508: } 23 \% \\
\text { G85E: } 8.7 \% \\
\text { N1303K: } 5.4 \%\end{array}$ & $\begin{array}{l}\text { Delf508: } 16.6 \% \\
\text { N1303K: } 16.6 \% \\
\text { D1152H }\end{array}$ & 0.05 \\
\hline
\end{tabular}

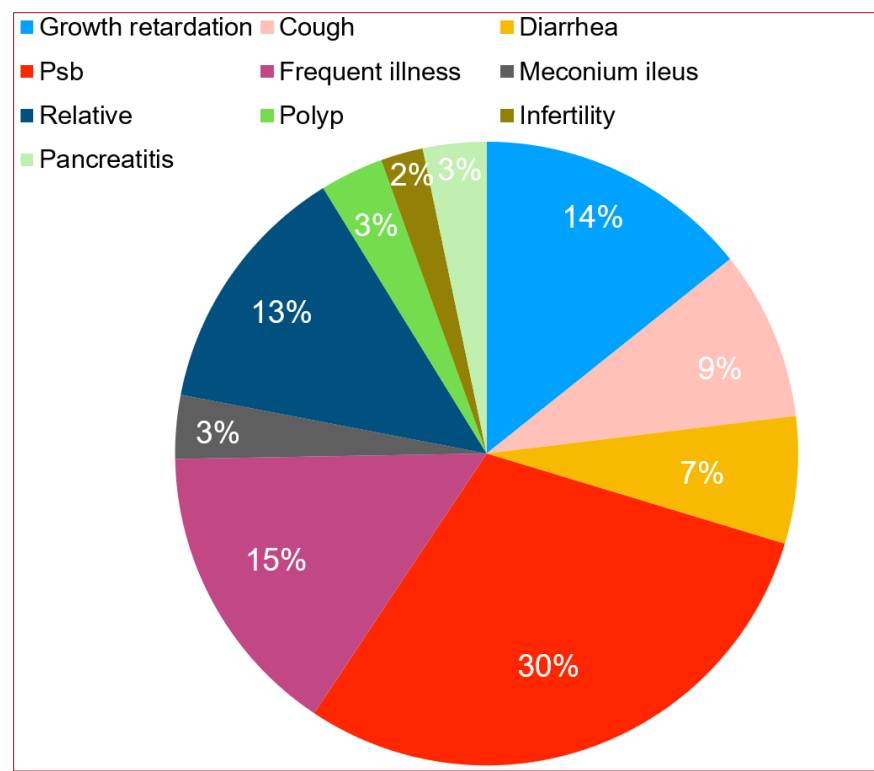

Figure 1. Symptoms and clinical findings of CF patients at the admission

The most common allele was delf508 with $23.1 \%$, followed by N1303K with $8.9 \%$. In $13.8 \%$ ( $n=9)$ patients, the delf508 mutation was found to be homozygous. In $10.7 \%(n=7)$ patients, this mutation was identified in a single allele of the patients. The mutation analysis of the patients are shown in Table 2.
Table 2.

The mutation alleles of the patients

\begin{tabular}{lc}
\hline Allele gene & Patients $\mathbf{n}(\%)$ \\
\hline Delf508 & $26(23.1 \%)$ \\
N1303K & $10(8.9 \%)$ \\
G85E & $8(7.1 \%)$ \\
D1152H & $6(5.3 \%)$ \\
I1051V & $4(3.5 \%)$ \\
c.3849+5G>A & $4(3.5 \%)$ \\
R334W & $4(3.5 \%)$ \\
delTA & $3(2.6 \%)$ \\
G542X & $3(2.6 \%)$ \\
\hline
\end{tabular}

R785X, L568F, F1052V, 2694T/G, 4521G/A, and L732X were seen in only 2 alleles and $125 \mathrm{G}<\mathrm{C}, 2789+56>\mathrm{A}$, E217G, D110H, R170H, 1248+1G>A, G576A, R668C, S1455X,1234VI, 2183delAA, I1295, E831X were seen in only 1 allele.

The last percentiles of patients were as follows: heights and body weights of $26 \%(n=13)$ patients were below the $3^{\text {rd }}$ percentile. Five $(7.6 \%)$ of our patients were diagnosed as having allergic bronchopulmonary aspergillosis (ABPA). Two patients who developed ABPA were among the patients who died. 
Throat and sputum cultures were taken in the regular follow-up of our patients. The mean age of the first microorganisms growing in throat and sputum cultures is 10.8 years.

Pseudomonas aeruginosa was the first microorganism that detected in $29.2 \%(n=19)$ patients, Staphylococcus aureus was first to detected in $18 \%(n=12)$ patients. Chronic pseudomonas colonization was seen in $39.3 \%$ $(n=24)$ patients and $14.5 \%(n=4)$ of the patients with Methicillin-resistant Staphylococcus aureus (MRSA). No nontuberculous mycobacteria detected was observed in any patients. The patient who had Burkholderia cepacia also died. Nine (14.3\%) patients were diagnosed as having CFRD, and they received insulin treatment. Two patients who developed diabetes were among the patients who died. The glycated hemoglobin ( $\mathrm{HbA} 1 \mathrm{c})$ values of $15.2 \%(n=10)$ of patients were 6 years and over.

Osteopenia was observed in $60 \%(n=39)$ of patients, and osteoporosis in two patients who could be evaluated with bone densitometry over the last 5 years.

Twenty-five (35\%) patients regularly performed airway cleaning. The treatments used by patients are shown in Table 3.

\section{Table 3}

The treatments prescribed to the patients

\begin{tabular}{lcc}
\hline Treatment & Patient number & Patient percentage (\%) \\
\hline Pancreatic lipase & 51 & 78.8 \\
Dornase alfa & 49 & 75.4 \\
Inhaler antibiotic & 8 & 11.7 \\
Inhaler mannitol & 25 & 39 \\
Ursodeoxycholic acid & 24 & 21.1 \\
Inhaler Ventolin & 38 & 57.6 \\
Inhaler corticosteroid & 22 & 34.6 \\
Azithromycin & 4 & 5.7 \\
Oral corticosteroid & 22 & 34.6 \\
Hypertonic saline & 16 & 25 \\
\hline
\end{tabular}

One $(1.7 \%)$ patient who had oxygen support was also waiting for lung transplantation. One patient who had non-invasive mechanic ventilation support died.

One $(1.5 \%)$ patient underwent lung transplantation, and two $(3 \%)$ patients are waiting to undergo lung transplantation.

Eighteen $(27.6 \%)$ patients are using enteral products in addition to their diets. Two patients underwent gastrostomy.

In the last 1 year, $25.4 \%(n=16)$ of our patients received IV antibiotics for lung exacerbations. In terms of the gastrointestinal system (GIS) complications of the disease, $4.6 \%(n=3)$ patients developed cirrhosis, and three underwent liver transplantation.

Fifteen percent of the patients had vitamin A deficiency, $16.6 \%$ had vitamin $E$ deficiency, and $64.6 \%$ had vitamin $\mathrm{D}$ deficiency.

Considering the socioeconomic level of our patients, $40 \%$ $(n=6)$ adult patients worked full time. Nineteen $(29.2 \%)$ patients are receiving primary education, and $34.6 \%$ $(n=18)$ patients are studying in high school. Three $(5.2 \%)$ patients are at university. Eight patients are married, and three have children. We have three patients who are receiving treatment for infertility.

\section{Discussion}

$\mathrm{CF}$ is the most common disease with an autosomal recessive inheritance pattern in Caucasians, together with a carrier frequency of approximately $1 / 25$ and a live birth incidence of $1 / 2000-3500.11,12$ The risk of developing the disease increases in countries such as Turkey, where consanguineous marriage is common. According to the data of the 2008 Turkey Demographic and Health Research, consanguineous marriage had an extremely high rate, $24.1 \%,{ }^{8}$ its frequency in the Central Anatolia Region was found as 2.9/10,000 in the study of Hangul et al. ${ }^{6}$

In light of the current information about CF, early diagnosis, new treatment methods, increase in families' awareness about the disease, and treatment adherence prolongs the lives of patients with CF, worldwide. Therefore, with the increase in the number of appropriate centers where adult patients with CF can be monitored, the number of children with CF has remained stable in the United Kingdom over the years, but the number of patients with $\mathrm{CF}$ in adult clinics is increasing. This increase is also predicted to continue in this way in all countries in the coming years. ${ }^{1}$

According to the CFFPR, the adult group increased from $29.4 \%$ to $54.6 \%$ when 1988 and 2019 were compared, and in the 2018 patient data report of the European Cystic Fibrosis Society (ECFS), $51.2 \%$ of patients were reported to be adults. According to the national cystic fibrosis registry system in Turkey (UKKS), the oldest patient was aged 41 years, and the adult patient group constituted only $4.6 \%$ of the total group. In our study, on the other hand, the adult group accounted for $6.5 \%$ of the entire group. It is still observed to be low when compared with Europe and America. According to the CFFPR, the adolescent group formed $25 \%$ of all patients. The reason for the higher number of patients in the adolescent age group than in the adult group was that pediatric chest diseases cover a period of 12 years, and every diagnosed patient had reached an adolescent age within this period, whereas the other group was included in the follow-up with late diagnosis.

The most common clinical presentation was PSB in the adolescent group and bronchiectasis in the adult group. There was a significant difference between the groups in terms of bronchiectasis and PSB $(p=0.035, p=0.004$, respectively).

According to the CFFPR, the median survival age was 26 years in 1988; however, the median survival age was 47.4 (range, 44.2-50.3) years in 2019. These data have shown that CF is now a disease monitored in childhood, and lifespans can also be prolonged with meticulous monitoring and treatment in adulthood.

It is important to provide nutrition and growth at an optimal level in the follow-up of individuals with CF 
because nutritional status is directly related to respiratory functions and lifespan..$^{12}$ In patients with low BMI, FEV 1 drops, and a low $F E V_{1}$ leads to frequent hospitalization, and frequently sickness causes a further drop in BMI.6,13 According to the CFFPR, the targeted BMI for children with CF should be $\geq 50$ percentile in older children and adolescents. In line with this report, when adult BMI values are above $22 \mathrm{~kg} / \mathrm{m}^{2}$ in women and $23 \mathrm{~kg} / \mathrm{m}^{2}$ in men, $\mathrm{FEV}_{1} \%$ rises above 60 , and the increase in $\mathrm{FEV}_{1}$ continues the same way as in increased BMI values..$^{14,15}$ Considering the ECFS 2018 data, BMI was reported as $20.7-21.7 \mathrm{~kg} / \mathrm{m}^{2}$ for the $18-38$ years' age range, and 23 $\mathrm{kg} / \mathrm{m}^{2}$ for those aged 38 years and over. In our study, there was a similarity with the results of Europe in both sexes. Malnutrition was observed in $20 \%(n=14)$ of patients in total. This showed that we need to be more careful about the nutrition of malnourished patients and monitor them closely for vitamin support and weight. Improvements in the nutrition of patients will provide better lung functions and thus increase the survival of our patients.

Annual changes in $\mathrm{FEV}_{1}$ are followed for patients with $\mathrm{CF}$. Improving $\mathrm{FEV}_{1}$ and preventing its decrease are the main objectives of treatment methods developed for protecting the lungs and keeping them healthy in CF. According to the CFFPR, the FEV 1 rate has been reported as $88 \%$ for age 18 years and $69 \%$ for age 30 years. For the ECFS, mean $\mathrm{FEV}_{1}$ is $92 \%$ for the adolescent group, whereas it is $69 \%$ in adults. ${ }^{16}$ According to the cystic fibrosis patient registry in Turkey (UKKS) the estimated mean $\mathrm{FEV}_{1}$ is $86 \% .{ }^{17}$ In our patients, the mean $\mathrm{FEV}_{1}$ value was found as $82.94 \pm 25.22 \%$. There was a significant difference between the groups $(p=0.001)$. Due to the low $F E V_{1}$ in the adult group, the need for lung transplantation has a higher rate in this group. In seven patients, FEV was found to be below $40 \%$. Regular and effective cleaning of the airway, detection and treatment of lung inflammation, and chest physiotherapy are factors that slow down the $\mathrm{FEV}_{1}$ decrease in our patients. In our study, $25 \%$ of our patients cleaned their airway. We thought that our patients did not perform their respiratory tract physiotherapy regularly. We associated this result with the lack of awareness of our patients because there were no respiratory tract physiotherapists in our clinics.

Frequent infections in $\mathrm{CF}$, colonizations, and lung inflammation are significant causes of lung damage. Infections that cause this damage are Haemophilus influenzae and Staphylococcus aureus in young ages, and Pseudomonas aeruginosa is observed as age increases. The rarer ones are bacteria with multiple antibiotic resistance such as Burkholderia cepacia, Stenotrophomonas maltophilia, and A. xylosoxidans. According to the CFFPR, culture positivity was obtained in $45.3 \%$ of patients for Pseudomonas aeruginosa, and chronic pseudomonas colonization was seen in $28.3 \%$; MRSA by $25 \%$, Stenotrophomonas maltophilia by $12 \%$, and Burkholderia cepacia by $3 \%$. According to the ECFS, the average incidence of chronic pseudomonas infection was $30 \%$ in total, $24.4 \%$ in the adolescent group, and $48 \%$ in the adult group. In the UKKS, chronic pseudomonas infection was reported as $20.9 \%$, chronic Staphylococcus aureus as $25.2 \%$, and Burkholderia cepacia as $1.2 \%$. In our patients, similar results to the CFFPR and ECFS were obtained in terms of chronic pseudomonas reproduction, and there was no significant difference between the groups $(p>0.05)$. MRSA colonization reproduction was found at a lower rate. No nontuberculous mycobacteria reproduction was observed in the patients. This was associated with clinical polymorphism and the low yield of bacteriologic tests in tuberculosis. In CFFPR, the first pseudomonas infection age was 5 years, whereas it was 2 years in our patients. It was 9 for Stenotrophomonas maltophilia, and 43 in our patient group. For MRSA, it was 11, which was similar to our patient group.

In patients with CF, pulmonary exacerbation is characterized by newly developed respiratory system symptoms and physical examination findings. It is important to identify and treat exacerbations because they affect mortality. In the CFFPR data, pulmonary exacerbation was observed in $42 \%$ of adults and $22 \%$ of adolescents. In the UKKS, pulmonary exacerbation was observed as $19.2 \%$ in patients below the age of 12 years and above $29.2 \%$ in patients older than 12 years. In our study, there was no significant difference between the groups $(p>0.05)$. The lower rates compared with Europe are thought to be related to the patients not being aware of their symptoms at presentation.

ABPA is seen in $1-15 \%$ of cases and may cause lung findings to become more severe. ${ }^{9}$ Our results were similar to the literature.

Recurrent sinusitis, pansinusitis, and nasal polyps are common complications in adolescents. ${ }^{18}$ In the CFFPR data, nasal polyps accounted for $10.4 \%$, and $1.4 \%$ of them underwent surgery. The Incidence of sinusitis is reported as $21 \%$ in adolescents and $56 \%$ in adults. In the UKKS, sinusitis was reported at a rate of $9.4 \%$. In our study, we observed a higher value and there was no significant difference between the groups $(p>0.05)$. We thought that the higher incidence of sinusitis and polyps in our patients was associated with sinusitis and polyp development resulting from insufficient irrigation of the sinus.

Hemoptysis and pneumothorax, which are complications seen in adult patients, are usually common in patients who have severe pulmonary disease, have $\mathrm{FEV}_{1}$ values below $40 \%$, and who develop chronic colonization..$^{19}$ In the CFFPR data, pneumothorax requiring chest drain was found as $0.2 \%$ and hemoptysis as $3 \%$. In the UKKS, pneumothorax was found as $0.1 \%$, and hemoptysis as $0.5 \%$. In our patient group, when compared with Europe and Turkey, the pneumothorax rate was similar. Our patient with recurrent pneumothorax had an $\mathrm{FEV}_{1}$ value of 30 and chronic pseudomonas colonization. This patient underwent lung transplantation. Hemoptysis was found as $9.2 \%$ in our patient group, higher than the European and Turkish means. This was observed in pulmonary exacerbation periods and thought to be related to the severity of bronchiectasis. In our study, bronchiectasis was found as $66.6 \%$ in the adult patient group, which was substantially higher than that of the adolescent group. This situation could be associated with early diagnosis, early initiation of treatment, and treatment and family compliance in the adolescent group. 
According to the CFFPR data, asthma was found as $28 \%$ in the adolescent group, and $35 \%$ in the adult group. We found similar results in our patients. There was no significant difference between the groups $(p>0.05)$.

The most common causes of mortality and morbidity in CF are respiratory system inflammation and infection. The second cause of mortality is transplantation complications, and thirdly, CF-related liver disease. ${ }^{19}$ According to the CFFPR, the incidence of cirrhotic liver disease is $3.3 \%$, and for the UKKS, the incidence of chronic liver disease is $7.9 \%$. In our patient group, the incidence of cirrhosis was similar. Three of our patients underwent transplantation, and one patient died in the acute period of the transplantation. Two patients are clinically stable. These results suggest that liver involvement in CF is not uncommon, and we have two patients awaiting transplantation.

Other gastrointestinal complications observed in adolescence and adulthood are reported, according to the CFFPR: distal intestinal obstructive syndrome (DIOS) (2.3\%), fibrosing colonopathy $<0.1 \%$, and gastroesophageal reflux (GER) (36\%). For the UKKS, GER was $4 \%$. In our patients, gastrointestinal complications were similar to the literature. However, there was a significant difference of GER in the adolescent and adult groups $(p=0.004)$. It was thought that GER might be related to verbal questioning in the adult group.

Children with a chronic disease such as CF are at risk for osteoporosis and osteopenia due to factors such as disease and treatment-related factors, risky nutrition, and reduced physical activity. The risk increases as the severity of lung disease and malnutrition increase. . $^{15,16}$ According to the CFFPR data, osteopenia was found by $10 \%$, and osteoporosis by $3 \%$. For UKKS, the incidence of osteoporosis is $2.4 \%$. In our patient group, osteopenia was lower and osteoporosis was similar to the bone mineral density measurements of the last 5 years. In these patients, it is important to perform BMI measurements and to provide vitamin support.

CFRD is now a more common condition due to the increase in the survival of patients with CF. CFRD significantly increases mortality in patients with CF. Although the risk of diabetes in the first 10 years is the same with children without the disease, the risk increases in adolescents and adults. ${ }^{7,19}$ According to CFFPR data, the incidence of CFRD is $31 \%$ in adults and $5 \%$ in adolescents. In our patients, similar results were found with the literature and there was a significant difference between the adolescent and adult groups $(p=0.017)$.

According to the CFFPR, the total number of patients who had lung transplantation in 2018 was 253, only one of our patients underwent transplantation. One of our patients is still waiting to undergo transplantation, and two patients have transplantation requests pending.

In our country, because the patients' weights are less, especially in childhood and adolescence, clinical experience is limited when it comes to lung transplantation for adolescent patients; one patient $(0.6 \%)$ who is waiting for transplantation continuously needs oxygen support. This is rate is $10.8 \%$ in the CFFPR.
In our country, patients with irregular follow-up or discontinuation of follow-up constitute a significant problem in chronic patient monitoring. According to CFFPR, the rate of patients with irregular follow-up was $2.9 \%$. This was high $(12.3 \%)$ in our study. We thought this was related to families being bored with the process and not perceiving the importance of the disease.

There are about 2000 mutations identified related to the disease in genetic tests today. The most common mutation in the disease is delta F508. ${ }^{1,2}$ The frequency of this mutation in the chromosome alleles of patients with CF in Northern Europe and North America is 70$80 \%$. According to the CFFPR, homozygous delta F508 mutations were identified in $40 \%$ of patients, heterozygous mutations were seen in $41 \%$, and other mutations in $19 \%$ of patients. In the UKKS delta F508 was the most frequent mutation with $28 \%$, followed by N1303K at $4.9 \%$. In our study, we found a similar result. There was no significant difference between the groups $(p>0.05)$. This was thought to be associated with the difference in the genetic distribution compared with Northern Europe and America because our country is located on migratory routes.

Nutrition and growth at an optimal level is a significant part of the treatment of patients with CF. ${ }^{13,14}$ The pancreas is an important organ in CF, and pancreatic insufficiency (PI) is encountered in around $85-90 \%$ of patients with CF. If PI is not diagnosed and treated on time, growthdevelopmental delay, malnutrition, short height, vitamin and mineral deficiencies will be unavoidable. Pancreatic enzyme replacement therapy (PERT) is supported for treating impaired fat absorption due to pancreatic insufficiency. ${ }^{8,9}$ According to CFFPR, the use of pancreatic enzyme therapy was $84.9 \%$. In the ECFS data, the rate was $83 \%$. In the UKKS, it was $87.4 \%$. In our patients, it was $78.8 \%$. These results suggest that awareness on the use of PERT is the same as in Europe and America.

Respiratory system involvement is the most important cause of morbidity and mortality in CF, and clearance of sputum constitutes one of the most important points of treatment. ${ }^{7}$ According to the CFFPR, $91.4 \%$ of patients used dornase alfa, $73.4 \%$ hypertonic saline, $64.2 \%$ azithromycin, and inhaled antibiotics was $15 \%$. In the ECFS, the use of hypertonic saline was $54 \%$, and inhaled antibiotics was $44 \%$. In UKKS, $86.7 \%$ of patients used dornase alfa, $8 \%$ hypertonic saline, and $6.3 \%$ azithromycin. In our study, $75.4 \%$ of patients used dornase alfa, $11.7 \%$ inhaled antibiotics, $57.6 \%$ inhaled beta-agonist, $25 \%$ hypertonic saline, and $5.4 \%$ azithromycin. This suggests that our patients are conscious and compliant about the use of dornase alfa and hypertonic saline, but not about the use of azithromycin.

According the ECFS, mortality was $1.3 \%$. In our study, the median age of mortality was 23.1 in the adult group, where the youngest age was 20 years and the oldest 28 years. In adolescents, the median age of mortality was 13.5 years. In our study, mortality was $7.6 \%$ in all patients, whereas it was $20 \%$ in the adult group. There was a significant difference between the groups $(p=0.004)$. This was thought to be associated with the late diagnosis in the adult patient group and the progression of the disease. 
According to the CFFPR, $53 \%$ of adults with CF have fulltime or part-time jobs, $30.9 \%$ are university graduates, and $30 \%$ were still studying at university. In our study, $40.2 \%$ of the adult patient group had full-time jobs, $6.1 \%$ were university graduates, and $4.6 \%$ were still studying at university. The lower rate of working patients compared with European countries can be explained by the observation of a higher female patient rate. Besides, the lower rate of education was thought to be related to the fact that families did not send their children to school for protection because they became sick frequently.

The number of pregnancies reported to the CFFPR between 2008 and 2018 was 280, we had two pregnant patients. We thought this could be related to the lower number of adult patients than the overall number of patients, and the lower number of married female patients in our study.

\section{Conclusion}

With early diagnosis and treatment, lifespans of patients with $\mathrm{CF}$ are prolonged, and they can reach adulthood. Multidisciplinary follow-up together with other departments, especially the department of adult chest diseases after the age of 18 years, will affect the life qualities of patients.

Author Contributions: All of the authors declare that they have all participated in the design, execution, and analysis of the paper, and that they have approved the final version.

Conflict of Interest: The authors have no conflict of interest to declare.

Ethics Committee Approval: Necmettin Erbakan Üniversity,Meram Faculty of Medicine Ethics Committee was obtained for this study (date: 18.09.2020, number: 2020/2815).

Financial Disclosure: The authors declared that this study has received no financial support.

Informed Consent: The patient consent form could not be obtained because the study was retrospective and informations were obtained from the medical records of the patients.

\section{References}

1. Romeo G, Devoto M, Galena LJV. Why is the cystic fibrosis gene so frequent? Hum Genet. 1989; 84:1-5. [CrossRef]
2. Kerem B, Rommens JM, Buchanan JA, et al. Identification of the cystic fibrosis gene: genetic analysis. Science. 1989;245:10731080. [CrossRef]

3. Bobadilla JL, Macek M Jr, Fine JP, Farrell PM. Cystic fibrosis: a worldwide analysis of CFTR mutations--correlation with incidence data and application to screening. Hum Mutat. 2002;19:575-606. [CrossRef]

4. Clain J, Lehmann-Che J, Duguépéroux I, et al. Misprocessing of the CFTR protein leads to mild cystic fibrosis phenotype. Hum Mutat. 2005;25:360-371. [CrossRef]

5. Moran A, Doherty L, Wang X, Thomas W. Abnormal glucose metabolism in cystic fibrosis. $J$ Pediatr. 1998;133:10-17. [CrossRef]

6. Hangül M, Pekcan S, Köse $M$, et al. The Incidence of Cystic Fibrosis in the Central Region of Anatolia in Turkey Between 2015 and 2016. Balkan Med J. 2019;36:179-183. [CrossRef]

7. Yalçın E. Clinical findings and diagnosis in cystic fibrosis. In: Dağlı E, Karakoç F; eds. Pediatric Chest Diseases. Istanbul: Nobel Matbaacılık, 2007;225-230.

8. Davies JC, Alton EW, Bush A. Cystic fibrosis. BMJ. 2007;335:12551259. [CrossRef]

9. Davis PB, Byard PJ, Konstan MW. Identifying treatments that halt progression of pulmonary disease in cystic fibrosis. Pediatr Res. 1997;41:161-165. [CrossRef]

10. Hacettepe University Institute of Population Studies (2009) Turkey Demographic and Health Survey, 2008. Hacettepe University Institute of Population Studies, Ministry of Health General Directorate of Mother and Child Health and Family Planning, T.R. Prime Ministry Undersecretary of State Planning Organization and TÜBITAK, Ankara, Turkey.

11. Çullas İlarslan N, Özcan G, Yıldırım D, Günay F , Çobanoğlu N . Kistik fibrozis yenidoğan taraması sonrası yönlendirilen bebeklerin değerlendirilmesi: dört yıllık tek merkez deneyimi. Türkiye Çocuk Hast Derg. 2019;13:270-276. [In Turkish] [CrossRef]

12. Canadian Paediatric Society. Age limits and adolescents. Paediatr Child Health. 2003;8:577-578. [CrossRef]

13. Kalnins D, Durie PR, Pencharz P. Nutritional management of cystic fibrosis patients. Curr Opin Clin Nutr Metab Care. 2007;10:348354. [CrossRef]

14. Dodge JA, Turck D. Cystic fibrosis: nutritional consequences and management. Best Pract Res Clin Gastroenterol. 2006;20:531546. [CrossRef]

15. Borowitz D, Baker RD, Stallings V. Consensus report on nutrition for pediatric patients with cystic fibrosis. J Pediatr Gastroenterol Nutr. 2002;35:246-259. [CrossRef]

16. Sinaasappel M, Stern M, Littlewood J, et al. Nutrition in patients with cystic fibrosis: a European Consensus. J Cyst Fibros. 2002;1:51-75. [CrossRef]

17. Ryan MW. Diseases associated with chronic rhinosinusitis: what is the significance?. Curr Opin Otolaryngol Head Neck Surg. 2008;16:231-236. [CrossRef]

18. Haller W, Ledder O, Lewindon PJ, Couper R, Gaskin KJ, Oliver M. Cystic fibrosis: An update for clinicians. Part 1: Nutrition and gastrointestinal complications. J Gastroenterol Hepatol. 2014;29:1344-1355. [CrossRef]

19. Moran A, Doherty L, Wang X, Thomas W. Abnormal glucose metabolism in cystic fibrosis. $J$ Pediatr. 1998;133:10-17. [CrossRef] 